\title{
Resveratrol reduces the level of chronic systemic inflammation in stable coronary artery disease
}

\author{
Chekalina NI*, Shlykova OA, Mykytiuk MV, Izmailova OV, Vesnina LE, Kazakov YuM and Kaidashev IP
}

Higher State Educational Establishment of Ukraine, Ukrainian Medical Stomatological Academy, Poltava, Ukraine

\begin{abstract}
This study aimed to investigate the effects of plant polyphenol of resveratrol on chronic systemic inflammation indicators of stable coronary artery disease. 85 patients with coronary heart disease were recruited and prescribed a standard therapy ( $\beta$-blockers, statins, aspirin). 30 patients received resveratrol at a dose of $100 \mathrm{mg}$ daily and the other serves as the control group. Cytokines and the expression of mRNA gene of inhibitor of kappa $B \alpha(\operatorname{IkB} \alpha)$ of nuclear factor of transcription kappa

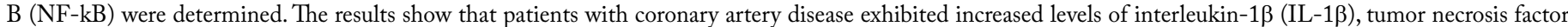
$(\mathrm{TNF} \alpha)$, and IL-10 in the blood. Resveratrol treatment led to a reliable reduction IL-1 $\beta$ and TNF $\alpha$, the content of IL-10 tended to reduce. In addition, we failed to notice any significant difference in the inhibitor of kappa $\mathrm{B} \alpha(\mathrm{IkB} \alpha)$ of nuclear factor of transcription kappa $\mathrm{B}$ between groups. In conclusion, in patients with coronary artery disease, resveratrol shows anti-inflammatory properties via reducing the content of proinflammatory cytokines in the blood, such as IL-1 $\beta$ and TNF $\alpha$.
\end{abstract}

\begin{abstract}
Abbreviations and symbols: CSI: Chronic systemic inflammation; CHD: Coronary heart disease; CK: Cytokines; TNFa: Tumor necrosis factor; IL-1 $\beta$ : Interleukin-1 $\beta$; IL-10: Interleukin-10; IkB $\alpha$ : Inhibitor of kappa B $\alpha$; NF-kB: Nuclear factor of transcription kappa B; Real-time PCR: Polymerase chain reaction in real time; ASVD: Atherosclerosis; ET: Vascular endothelium; COX: Cyclooxygenase; LOX: Lipoxygenase; IKKa: IkB-kinase $\alpha$; eNOS: Endothelial synthetase of nitric oxide; TET: Treadmill exercise test; HF: Heart failure; LVEF: Left ventricular ejection fraction; EQ-5D-3L: Health-related quality of life questionnaire 3 level versions; EQ-5D-VAS: EQ-5D visual analogue scale; SIRT1: Sirtuin 1; NO: Nitric oxide; EMP: Circulating endothelial microparticles; STAT1: Transcription activator transmitting a signal 1; IRF-1: Factor regulating interferon 1
\end{abstract}

\section{Introduction}

Atherosclerosis (ASVD) has been still relevant and unsolved problem of clinical medicine. Coronary heart disease (CHD), which morphological basis is ASVD, heads the list of the top 10 causes of death in the world and is accounted for $12.8 \%$. In Ukraine, CHD is among leading causes of cardiovascular mortality (68.8\%) [1].

Chronic systemic inflammation (CSI) is the pathogenetic basis of ASVD. Under the influence of damaging factors, such as free radicals, endo- and exotoxins, high blood pressure, etc., vascular endothelium (ET) is activated with the development of its systemic dysfunction: functioning molecular signaling cascades with increased synthesis of proinflammatory cytokines (CK) and adhesion molecules is enhanced, the transmembrane transport and regulation of vascular tone are disrupted [2]. These data substantiate the relevance of active search for CSI correction agents at ASVD in order to improve treatment.

Recently, researchers attention has been drawn to the polyphenolic compounds of plant origin. Polyphenols possess hydrophilic properties and play the role of free radical scavengers, which lead to their antioxidant effect. They also activate paraoxonase in the blood promoting hydrolysis of hydroperoxides [3]. Anti-inflammatory, anti-adhesive, angiogenic, vasodilative and many other properties of polyphenols have been found out, which are implemented mainly through effects on molecular targets of intracellular cascades [4].

One of the representatives of the plant polyphenol is phytoalexin resveratrol (3,4,5-trihydroxy-trans-stilbene) found in more than 30 kinds of plants and used in medicine as a natural extract and synthetic drug [5]. Resveratrol has a direct antiradical action by means of three hydroxyl groups in its chemical formula, regulates the activity of enzymes of cyclooxygenase (COX) and lipoxygenase (LOX), has antiinflammatory activity-it inhibits the pathogenic effect of a key factor of activating process of inflammation of NF- $\mathrm{kB}$ through inhibition of IkB-kinase $\alpha(\mathrm{IKK} \alpha)$, and has endothelio protective effect through activation of endothelial synthetase of nitric oxide (eNOS) as well [6-8]

The aim of our research was to study the effects of resveratrol on the CSI indicators in stable CHD.

\section{Materials and methods}

The study involved 85 people of both sexes ( 36 females and 49 males) aged 48-67, diagnosed with CHD, stable angina pectoris, FC II, HF 0 -I, the average risk. The selection of patients was carried out using an objective and instrumental examination: Rose angina questionnaires, SCORE table, bicycle ergometer and Doppler echocardiography. Every patient gave a written informed consent to participate in the research, according to the requirements of the Declaration of Helsinki. The criterion for inclusion into the study was signs of coronary

Correspondence to: Chekalina NI, Higher State Educational Establishment of Ukraine, Ukrainian Medical Stomatological Academy, Poltava, Ukraine, E-mail: chekalina.ni.med@mail.ru

Key words: coronary heart disease, resveratrol, chronic systemic inflammation, inflammatory signaling cascades

Received: October 26, 2016; Accepted: November 18, 2016; Published: November 22, 2016 
heart disease: stable angina pectoris, FC II. Exclusion criteria were the presence of Stage 2 heart failure (HF), Stage 2 hypertension, concomitant chronic diseases of bronchopulmonary system, liver and kidney dysfunction, endocrine or allergic disorders, diseases of the musculoskeletal system in the acute stage, cancer, thrombophlebitis. Bicycle ergometer was used with a continuously increasing step-by-step protocol of dosed physical load with duration of one stage of 2 minutes, the test was considered to be "positive" in the case of occurrence of objective evidence of myocardial ischemia during the trial. Every patient completed a load capacity of $75 \mathrm{~W}$, which corresponded to FC II. The presence of heart failure (HF) syndrome was established by clinical data and results of Doppler echocardiography. In the presence of clinical symptoms (shortness of breath with exertion, palpitations, fatigue) and decrease in left ventricular ejection fraction (LVEF), the diagnosis of $\mathrm{HF}$ was established. $43 \%$ of CHD patients had LVEF values of $45-50 \%$, corresponding to the degree of heart failure of Stage 1 with preserved systolic function, and the rest had ejection fraction greater than $50 \%$. All the patients showed signs of diastolic dysfunction of the left ventricle with impaired relaxation (Type 1). The degree of risk was being determined by the total assessment using SCORE table and LVEF values that in all patients of study groups was less than $3 \%$ of annual mortality risk (the average level) [9]. Every patient was prescribed a standard CHD therapy: along with recommendations for lifestyle (diet therapy, dosed physical exertion, smoking cessation), beta-blockers (5 $\mathrm{mg}$ of bisoprolol once a day in the morning), statins (10 $\mathrm{mg}$ of atorvastatin once a day at bedtime) and $75 \mathrm{mg}$ of aspirin at bedtime were prescribed. After stabilization of the clinical course of CHD in a month after the basic treatment patients were divided into the study group ( 30 people) and comparison ones ( 55 people) by random sampling and examining with clinical and laboratory methods.

For objectification of patients' condition the Health-Related Quality of Life Questionnaire 3 level version (EQ-5D-3L) with the estimation of EQ-5D index and visual analogue scale (EQ-5D-VAS) data analysis were used [10].

To assess the level of CSI, the level of cytokines (i.e. tumor necrosis factor (TNF $\alpha$ ), interleukin-1 $\beta$ (IL-1 $\beta$ ), and IL-10) in the blood was determined via immunoenzymatic method using the test system "Vector-Best" (Novosibirsk) based on the solid-phase "sandwich"variant of immunoenzymatic analysis with mono- and polyclonal antibodies [11]. The expression of the gene of inhibitor of kappa $B$ $a(\mathrm{IkB} \alpha)$ in peripheral blood mononuclear cells was determined by polymerase chain reaction in real time (real-time PCR) using the DT Light DNA amplifier ("DNA Technology", Russia) [12]. To obtain cDNA, a set of reagents for the reaction of inverse transcription (SYNTOL, Russia) was used. The total RNA was isolated from biological sample using the reagent set "RIBO-zol-B" (AmpliSens, Russia). The sequence of primers for determining IkBa gene expression-F: 5'-GGC TGA AGA AGG AGC GGC TA-3', R: 5'-CCA TCT GCT CGT ACT CCT CG-3'. Amplification mode: 95.0-5 minutes-1 cycle; 62.0-40 seconds, $95.0-15$ seconds-40 cycles. As a reference gene the "housekeeping" gene GAPDH was used. For data analysis a relative $\mathrm{Ct}$ method of calculation by the formula $2^{-\Delta \mathrm{Ct}}$ and $2^{-\Delta \Delta \mathrm{Ct}}$ was applied.

After the examination of patients of the research group they were additionally prescribed resveratrol at a dose of $100 \mathrm{mg}$ once daily per os on the background of basic therapy; the comparison group continued taking basic therapy. The results of treatment were evaluated after 2 months by re-examination in the above mentioned amount. During the examination and treatment of patients any complications, allergic reactions or hypersensitivity to medicines were not found.
Statistical analysis of the results of the research was carried out using KyPlot program. The hypothesis of normal distribution was checked by Shapiro-Wilk test. When comparing these study groups before and after treatment, paired Student's t-test was used, for inappropriate distribution-Wilcoxon signed-rank test and Steel test for paired observations. When comparing data between groups, unpaired Student's t-test and Steel-Dwass test (nonparametric analogue of Tukey's range test) were used. Search for relations between variables was held using Pearson's correlation or, subject to maldistribution, Spearman's and Kendall's rank correlation. Data of statistical analysis were presented in the form of $\mathrm{X} \pm \sigma$, where $\mathrm{X}$ is an average value, $\sigma$ is an average square deviation. Due to improper distribution and characteristics of discontinuous series the data were given as Me (Q1Q3), where $\mathrm{Me}$ is a median, Q1 and Q3 are the first and third quartiles. Data differences were considered to be significant at a level of $\mathrm{p}<0.05$ [13].

\section{Results and discussion}

Mean EQ-5D-index before treatment in patients with coronary artery disease was $0.738 \pm 0.061$, EQ-5D-VAS-55.63 \pm 5.38 . After 2 months of treatment patients treated with resveratrol more often than the comparison group patients noted the appearance of vitality, efficiency improving, reducing the number and duration of episodes of pain in the heart. EQ-5D-index $(\mathrm{p}<0.001)$ and values by EQ-5D-VAS scale $(\mathrm{p}<0.001)$ decreased. In the comparison group EQ-5D-index also decreased $(<0.001)$ after treatment, EQ-5D-VAS did not significantly change ( $p>0.05)$. Data of EQ-5D questionnaire have been shown on Figure 1.

Patients with coronary artery disease have shown an increased content of IL-1 $\beta \quad(9.76 \pm 3.33 \mathrm{pg} / \mathrm{mL})$ (in healthy people-1.6 (confidence interval-0-11 pg/mL)), TNF $\alpha(9.11 \pm 2.43 \mathrm{pg} / \mathrm{mL}$ ) (in healthy people-0.5 (0-6) pg/mL), IL-10 content was $10.97 \pm 2.97 \mathrm{pg} /$ $\mathrm{mL}$ (in healthy people $-5(0-31) \mathrm{pg} / \mathrm{mL}$ ), corresponding with modern scientific data on changes in the CK level in terms of atherogenesis $[2,14]$. IL- $1 \beta$ and TNF $\alpha$ are one of the leading mediators of inflammatory response, inducing production of proinflammatory $\mathrm{CK}$, chemoattractants, adhesion molecules, growth factors through increasing the transcriptional activity of NF-kB.

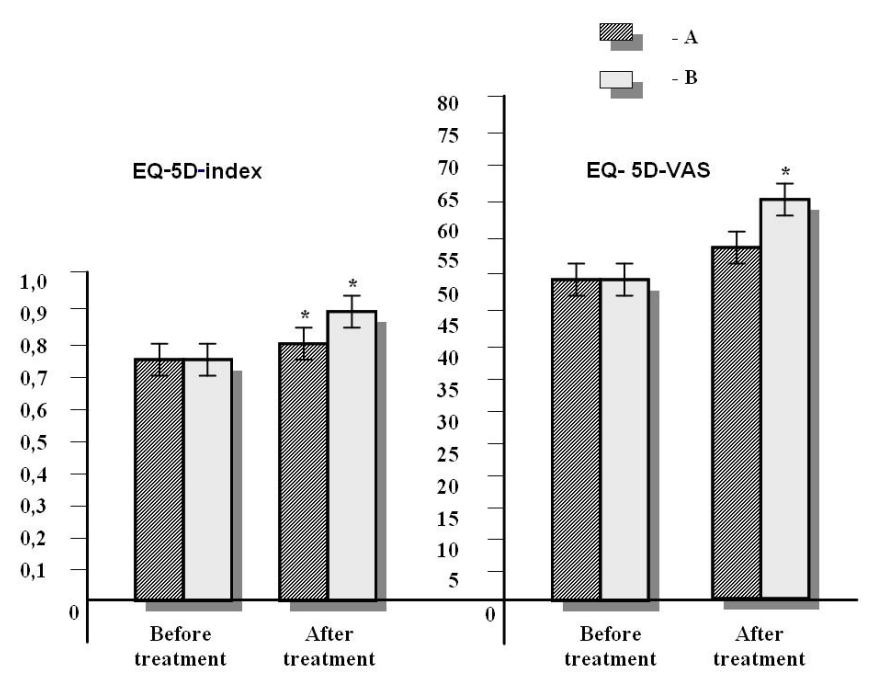

Figure 1. Dynamics of subjective status of patients according to the questionnaire EQ5D-3L [*: Reliable difference between indicators before and after treatment; A: Group of comparison; B: Group of investigation (resveratrol)]. 
After 2 months of therapy with resveratrol in patients there was a decrease of the level of CK (IL- $1 \beta$ and TNF $\alpha$ ), and the tendency to lower levels of IL-10 $(0.05>\mathrm{p}<0.1)$ was noted (Table 1$)$. However, in the comparison group presumable changes in the levels of the $\mathrm{CK}$ were not found, despite the statements on anti-inflammatory effect of statins [15]. Perhaps for pleiotropic anti-inflammatory effect larger therapeutic doses of statins are necessary, but with building-up a dose the probability of complications increases, especially in chronic forms of coronary artery disease (according to large-scale studies TNT, IDEAL) [16]. Therefore, the combination of statins with resveratrol can afford to get the necessary pathogenetically valid therapeutic effect on the ability to titrate the dose of statins, focusing exclusively on the blood lipid spectrum and levels of transaminases with guaranteed anti-inflammatory effect from the lowest doses due to the combined potential effect of these drugs.

Recent scientific studies have shown that effectiveness of resveratrol to reduce the level of inflammatory $\mathrm{CK}$ is implemented by several mechanisms: by direct antioxidant action as free radical scavenger due to the presence of $\mathrm{OH}$-groups, by activation of catalase, superoxide dismutase, increased levels of glutathione transferase, peroxidase and reductase, decreased activity of COX and LOX, regulation of nitric oxide (NO) synthesis, increased expression level of protein sirtuin 1 (SIRT1) providing density of histone backbone and preventing activation of IKKa $[17,18]$. IKKa subunit has the greatest importance in the structure of the IKK because being activated it destroys IkBa connection with the dimmer NF-kB (p50/p65). NF-kB p65 (Rel A) subunit, which is the gene transcription factor of molecules of inflammatory response, is translocated into the nucleus [19]. Each of these mechanisms can contribute to our results of reducing IL$1 \beta$ and TNF $\alpha$ under the influence of resveratrol. It has been proven that inactivation of NF-kB does not affect IL-10 expression processes, which can be an explanation for no reduction of CK in our study [20].

In patients treated with resveratrol, as in the comparison group, the expression of mRNA IkBa in blood mononuclear cells did not change significantly ( $\mathrm{p}=0.441$ and $\mathrm{p}=0.570$ respectively). IkBa retains $\mathrm{NF}-\mathrm{kB}$ in an inactive state in the cytosol of cells, preventing the transcription of inflammatory molecules. Reduced synthesis of proinflammatory CK in

Table 1. Cytokines levels in the blood serum of the subjects of the study.

\begin{tabular}{|c|c|c|c|c|c|c|c|}
\hline \multirow[t]{2}{*}{ Group /Mark } & \multirow[t]{2}{*}{ Statistical Index } & \multicolumn{2}{|l|}{ TNF $\alpha, p g / m l$} & \multicolumn{2}{|l|}{ IL-1 $\beta, p g / m l$} & \multicolumn{2}{|l|}{ IL-10, pg/ml } \\
\hline & & Before therapy & After therapy & Before therapy & After therapy & Before therapy & After therapy \\
\hline \multirow[t]{3}{*}{ Group of comparison } & $\mathrm{X}$ & 8.53 & 8.34 & 9.46 & 7.16 & 10.51 & 8.72 \\
\hline & $\sigma$ & \pm 3.24 & \pm 2.17 & \pm 2.98 & \pm 2.98 & \pm 3.33 & \pm 3.51 \\
\hline & & \multicolumn{2}{|l|}{$\mathrm{p}=0.866$} & \multicolumn{2}{|l|}{$\mathrm{p}=0.127$} & \multicolumn{2}{|l|}{$\mathrm{p}=0.134$} \\
\hline \multirow[t]{3}{*}{ Group of investigation (resveratrol) } & $\mathrm{X}$ & 9.69 & 7.28 & 10.05 & 6.98 & 11.41 & 9.39 \\
\hline & $\sigma$ & \pm 1.63 & \pm 2.18 & \pm 3.67 & \pm 2.52 & \pm 2.61 & \pm 3.06 \\
\hline & & \multicolumn{2}{|l|}{$\mathrm{p}=0.013$} & \multicolumn{2}{|l|}{$\mathrm{p}=0.002$} & \multicolumn{2}{|l|}{$\mathrm{p}=0.055$} \\
\hline
\end{tabular}

$\mathrm{X}$ : The sample mean; $\sigma$ : Standard deviation; $\mathrm{p}$ : The probability

Table 2. Level of mRNA IkB $\alpha$ expression in peripheral blood mononuclear cells of the subjects of the study.

\begin{tabular}{|c|c|c|c|c|c|}
\hline \multirow[t]{2}{*}{ Group / Mark } & \multirow{2}{*}{$\begin{array}{l}\text { Statistical } \\
\text { index }\end{array}$} & \multicolumn{2}{|c|}{ Group of comparison } & \multicolumn{2}{|c|}{ Group of investigation (resveratrol) } \\
\hline & & Before treatment & After treatment & Before treatment & After treatment \\
\hline \multirow{3}{*}{ Expression mRNA IkBa. $2^{-\mathrm{ACt}}$} & $\mathrm{X}$ & 0.0234 & 0.0253 & 0.0246 & 0.0220 \\
\hline & $\sigma$ & \pm 0.0198 & \pm 0.0155 & \pm 0.0131 & \pm 0.0092 \\
\hline & $\mathrm{p}$ & \multicolumn{2}{|l|}{0.570} & \multicolumn{2}{|l|}{0.441} \\
\hline \multirow[t]{2}{*}{$2^{-\Delta \Lambda C t}$} & $\mathrm{X}$ & \multicolumn{2}{|l|}{0.120} & \multicolumn{2}{|l|}{-0.142} \\
\hline & (min:max) & \multicolumn{2}{|l|}{$(-2.64:+2.83)$} & \multicolumn{2}{|l|}{$(-2.0:+1.87)$} \\
\hline
\end{tabular}

$\mathrm{X}$ : The sample mean, $\sigma$ : Standard quadratic deviation, (min:max): Extreme value variation series; $\mathrm{p}$ : The probability; *: Significant differences with the data of all groups before and after treatment $(\mathrm{p}<0.01)$

our study could be achieved by other mechanisms of resveratrol action, such as antioxidant one or activation of SIRT1 (Table 2).

The revealed ability of resveratrol to reduce the content of $\mathrm{MP} \mathrm{CD}_{2} 2^{+} \mathrm{CD} 40^{+}$demonstrates its anti-inflammatory and endothelioprotective properties [21]. It is known that increasing the number of EMP is the evidence of ET dysfunction. Predominant cause of this increasing may be determined by definition of the expression of appropriate molecules. Thus, for EMP of apoptotic endotheliocytes typical are CD31 and CD105 markers, for EMP, forming activated endotheliocytes,-CD32 (FcyRII), CD40 (TNFRSF5), CD54 (ICAM-1), CD62 (E та P), CD64 (FCGR1B), CD146 markers [22]. Inflammatory activation of $\mathrm{ET}$, which marker is $\mathrm{EMP} \mathrm{CD} 32^{+} \mathrm{CD} 40^{+}$studied, is considered to be an essential component of atherogenesis [23].

Arguably, resveratrol acts on one of the above-mentioned mechanisms inhibiting proinflammatory signal transduction. According to scientific data, inhibition of STAT1 (transcription activator transmitting a signal-1) or IRF-1 (factor regulating interferon 1), but not NF-kB, inhibits the expression of CD40 molecule at mRNA and protein level $[24,25]$. Despite the lack of probable reduction of mRNA IkBa expression under resveratrol in our study, a positive effect of resveratrol on levels of proinflammatory CK has been found out. In our opinion, inhibition of STAT1 or IRF-1 may also be one of the possible mechanisms of its action [26].

\section{Conclusions}

The intake of resveratrol in patients with stable coronary heart disease reveals a positive impact on the level of systemic inflammation during two-month treatment, unlike statins (atorvastatin) as a means of basic therapy. Along with improved clinical course, according to the EQ-5D questionnaire, resveratrol reduces the levels of proinflammatory CK IL- $1 \beta$ and TNF $\alpha$, but the impact of resveratrol on the $\mathrm{IkBa}$ expression at mRNA level has not been revealed. Mechanisms of anti-inflammatory activity of resveratrol are multimodal and cause CSI correction involving different signaling cascades. Taking into account proven anti-inflammatory effect by endpoints of assessment of the inflammatory response level, resveratrol should be considered as effective pathogenetically reasonable treatment for ASVD and coronary artery disease. 


\section{Conflict of interests}

Authors have accepted full responsibility for the conduct of the study, had access to the data, and controlled the decision to publish it. All authors have made a significant contribution to the preparation of the manuscript, acquisition and analysis of the study data. The study was funded by the authors. The results do not reflect the interests of any organizations and personalities. Our scientific work has no competing interest.

\section{References}

1. Kovalenko VM, Kornatsky VM (2015) Stres i hvoroby sistemy krovoobigu (Stress and cardiovascular diseases)-Kiev: SI "NSC "Institute of Cardiology named after Acad. MD Strazhesko.

2. Ridker PM (2016) From C-Reactive Protein to Interleukin-6 to Interleukin-1: Moving Upstream To Identify Novel Targets for Atheroprotection. Circ Res 118: 145-156. [crossref]

3. Hedrick CC (2015) Lymphocytes in atherosclerosis. Arterioscler Thromb Vasc Biol 35: 253-257. [crossref]

4. Watson AD, Berliner JA, Hama SY, La Du BN, Faull KF, et al. (1995) Protective effect of high density lipoprotein associated paraoxonase. Inhibition of the biological activity of minimally oxidized low density lipoprotein. J Clin Invest 96: 2882-2891. [crossref]

5. Manach C, Mazur A, Scalbert A (2005) Polyphenols and prevention of cardiovascular diseases. Curr Opin Lipidol 16: 77-84. [crossref]

6. Baur JA, Sinclair DA (2006) Therapeutic potential of resveratrol: the in vivo evidence. Nat Rev Drug Discov 5: 493-506. [crossref]

7. Imamura G, Bertelli AA, Bertelli A, Otani H, Maulik N, et al. (2002) Pharmacological preconditioning with resveratrol: an insight with iNOS knockout mice. Am J Physiol Heart Circ Physiol 282: H1996-H2003. [crossref]

8. Dolinsky VW, Chan AY, Robillard Frayne I, Light PE, Des Rosiers C, et al. (2009) Resveratrol prevents the prohypertrophic effects of oxidative stress on LKB1. Circulation 119: 1643-1652. [crossref]

9. Task Force Members, Montalescot G, Sechtem U, Achenbach S, Andreotti F, et al (2013) 2013 ESC guidelines on the management of stable coronary artery disease: the Task Force on the management of stable coronary artery disease of the European Society of Cardiology. Eur Heart J 34: 2949-3003. [crossref]

10. Amirdzhanova VN, Erdes Sh F (2007) Validacija russkoj versii obshchego oprosnika EUROQOL - 5D (EQ-5D) [Validation of the Russian version of the general questionnaire of EUROQOL-5D (EQ-5D)]. Scientific and practical rheumatology 3: $69-76$.

11. Egorov AM, Osipov AP, Dzantiyev BB, Gavrilova EM (1991) Teorija i praktika immunofermentnogo analza [Theory and practice of the immunofermental analysis]. Moscow: The higher school, 1991: 288.
12. Nolan T, Hands RE, Bustin SA (2006) Quantification of mRNA using real-time RTPCR. Nat Protoc 1: 1559-1582. [crossref]

13. Petri A, Sabine K (2010) Nagljadnaja medicinskaja statistika [Transparent medical statistics]. Moscow: GEOTAR-MED 2010: 43-68

14. Ahmad Z, Ng CT, Fong LY, Bakar NA, Hussain NH, et al. (2016) Cryptotanshinone inhibits TNF- $\alpha$-induced early atherogenic events in vitro. J Physiol Sci 66: 213-220. [crossref]

15. Musial J, Undas A, Gajewski P, Jankowski M, Sydor W, et al. (2001) Anti-inflammatory effects of simvastatin in subjects with hypercholesterolemia. Int J Cardiol 77: 247-253. [crossref]

16. Nissen SE, Tuzcu EM, Schoenhagen P, Brown BG, Ganz P, et al. (2004) Effect of intensive compared with moderater lipid-lowering therapy on progression of coronary atherosclerosis: a randomized controlled trail. GAMA 9: 1071-1080. [crossref]

17. Price NL, Gomes AP, Ling AJ, Duarte FV, Martin-Montalvo A, et al. (2012) SIRT1 is required for AMPK activation and the beneficial effects of resveratrol on mitochondrial function. Cell Metab 15: 675-690. [crossref]

18. Kaidashev IP (2012) Sistema sirtuinov i vozmozhnosti regulirovaniya eyo sostoyaniya v klinicheskoj praktike (obzor literatury) [Sirtuins system and the possibility of adjusting its status in clinical practice (review)]. Journal of NAMS of Ukraine 18: 418-429.

19. Kaidashev IP (2013) Aktivaciya yadernogo faktora kB kak molekulyarnoj osnovy patogeneza metabolicheskogo sindroma [Activation of nuclear factor-kB as a molecular basis of the pathogenesis of the metabolic syndrome]. Pathological Physiology and Experimental Therapy 3: 65-72.

20. Monaco C Andreakos E, Kiriakidis S, Mauri C, Bicknell C, et al. (2004) Canonical pathway of nuclear factor kappa $\mathrm{B}$ activation selectively regulates proinflammatory and prothrombotic responses in human atherosclerosis. Proc Natl Acad Sci 101: 5634-5639.

21. Chekalina NI, Kazakov YuM, Mamontova TV, Vesnina LE, Kaidashev IP (2016) Resveratrol more effectively than quercetin reduces endothelium degeneration and level of necrosis factor a in patients with coronary artery disease. Wiadomosci Lekarskie LXIX: 475-479.

22. Meziani F, Tesse A, Andriantsitohaina R (2008) Microparticles are vectors of paradoxical information in vascular cells including the endothelium: role in health and diseases. Pharmacol Rep 60: 75-84.

23. Chironi GN, Boulanger CM, Simon A, Dignat-George F, Freyssinet JM, et al. (2009) Endothelial microparticles in diseases. Cell Tissue Res 335: 143-151. [crossref]

24. Wormald S, Hilton DJ (2004) Inhibitors of cytokine signal transduction. J Biol Chem 279: 821-824. [crossref]

25. Knight RA, Scarabelli TM, Stephanou A (2012) STAT transcription in the ischemic heart. JAKSTAT 1: 111-117. [crossref]

26. Singh AK, Vinayak M (2016) Anti-Nociceptive effect of resveratrol during inflammatory hyperalgesia via differential regulation of pro-inflammatory mediators. Phytother Res 30: 1164-1171.

Copyright: (C2016 Chekalina NI. This is an open-access article distributed under the terms of the Creative Commons Attribution License, which permits unrestricted use, distribution, and reproduction in any medium, provided the original author and source are credited. 